\title{
Latent Variable Assessment of Outcomes in a Nurse-Managed Intervention to Increase Latent Tuberculosis Treatment Completion in Homeless Adults
}

\author{
Adeline Nyamathi and Judith A. Stein \\ University of California, Los Angeles
}

\author{
Anja Schumann \\ University of Greifswald
}

\author{
Darlene Tyler \\ University of California, Los Angeles
}

\begin{abstract}
Objective: To assess predictors of latent tuberculosis infection (LTBI) completion by using structural equation modeling (SEM) among homeless adults, a group at great risk for LTBI and active tuberculosis (TB). LTBI therapy is effective in stemming the progression to active TB, yet treatment adherence among homeless persons is difficult to attain. Design: By using SEM, the authors assessed predictors of LTBI completion among a sample of 494 homeless adults in Los Angeles, CA, who received either a nurse case-managed program (NCM) or a usual care program. Main Outcome Measures: Latent variables were created with the baseline variables of site type, age, intervention status, dissatisfaction with health care, depression, TB risk assessment, alcohol use, heroin or cocaine use, and TB knowledge. Outcome variables included many of the same baseline variables as well as treatment completion. Results: LTBI treatment completion (100\% adherence) was significantly and positively associated with participation in NCM, older age, and less heroin or cocaine use. NCM also predicted greater TB knowledge, greater ease of treatment, and more satisfaction with treatment (NCM completion rate $=64 \%$, control rate $=42 \%$ ). Conclusion: The culturally competent NCM program, combined with active tracking and incentives, was successful in a difficult-to-treat and highly transient population.
\end{abstract}

Keywords: homelessness, injection drug use, latent TB treatment completion, TB knowledge

Since 1993, the United States has experienced a resurgence in rates of reported tuberculosis (TB) cases, particularly among medically underserved and low-income people of color (Kimerling et al., 1999; Moss et al., 2000). TB prevalence in the general population of the United States is approximately 5.1 per 100,000 (Centers for Disease Control and Prevention [CDC], 2004). In contrast, rates in the homeless are estimated to be 20 - to 30 -fold higher, with the greatest burden in ethnic minorities and the foreign-born. Although overall prevalence rates of active TB and latent TB infection (LTBI) among the homeless nationwide are unknown, shelter- and clinic-based studies of homeless populations report cases of active TB as high as 52 per 100,000 (Hageman, 1998) and rates of purified protein derivative (PPD) positive skin tests ranging from $18 \%$ to $32 \%$ (Cheung, Hanson, Maganti, Keeffe, \& Matsui, 2002; Forman \& Kinney, 2003; Gelberg,

Adeline Nyamathi and Darlene Tyler, School of Nursing, University of California, Los Angeles; Judith A. Stein, Department of Psychology, University of California, Los Angeles; Anja Schumann, Institute of Epidemiology and Social Medicine, University of Greifswald, Greifswald, Germany.

Support for this research was provided by Grants DA01070-32 and DA11145 from the National Institute on Drug Abuse. We thank Gisele Pham for her secretarial and administrative contributions to this research project, and we also thank the homeless participants in this study.

Correspondence concerning this article should be addressed to Adeline M. Nyamathi, School of Nursing, University of California, Los Angeles, Box 951702, Los Angeles, CA 90095-1702. E-mail: anyamath@sonnet.ucla.edu
Andersen, \& Leake, 2000; Griffin \& Hoff, 1999; Moss et al., 2000; Zolopa et al., 1994).

The increased risk for LTBI and active TB among the homeless is attributable to high rates of immunodeficiency due to HIV/ AIDS, malnourishment and poor health, injection drug use (IDU), overcrowding, and limited access to preventive health and social services (A. B. Curtis et al., 2000; Daley, Hahn, Moss, Hopewell, \& Schecter, 1998; Munch et al., 2003; Nardell, McInnis, Thomas, \& Weidhaas, 1986; Selwyn et al., 1989; Small \& Fujiwara, 2001). TB risk is higher among injection drug users (IDUs) compared with the general population as IDU behaviors increase risk of HIV and bring people into proximity with others who may have active TB (R. Curtis et al., 1994). In addition, drug and alcohol use is associated with risky sexual activities that, in turn, increase risk for HIV and TB (Asch, Leake, Knowles, \& Gelberg, 1998). Studies conducted with homeless adults have found that up to $80 \%$ report a lifetime history of drug use; close to $20 \%$ report lifetime history of IDU (Nyamathi, Keenan, \& Bayley, 1998). Alcohol use is also pervasive among homeless adults (Nyamathi, Stein, Dixon, Longshore, \& Galaif, 2003).

Despite their higher risk for TB, there are major deficiencies in TB screening and treatment seeking among homeless persons. Barriers to treatment have included lack of availability of, or accessibility to, treatment drugs; lack of privacy and storage space; and lost or stolen medication (Gallagher, Andersen, Koegel, \& Gelberg, 1997; Nyamathi \& Shuler, 1990). Furthermore, seeking health care often is not a priority for homeless individuals, as they struggle to deal with higher level priorities, such as obtaining food, 
shelter, social service benefits, and, for some, drugs and alcohol (Gelberg et al., 1997; Nyamathi, Leake, Keenan, \& Gelberg, 2000).

The most effective strategy to prevent active TB among homeless persons with LTBI is completion of TB chemoprophylaxis (Jasmer, Nahid, \& Hopewell, 2002). However, compliance with medical regimens is especially difficult among homeless and drugusing persons, due in part to the instability in their lives (Gelberg et al., 1997; Herndon et al., 2003). This is particularly true for regimens that require daily dosing. Unfortunately, homeless adults have demonstrated only modest compliance with TB chemoprophylaxis (19\%-44\%), even when directly observed preventative therapy (DOPT) is used (Moss et al., 2004; Nazar-Stewart \& Nolan, 1992; Tulsky et al., 2000; White, Gournis, Kawamura, Menendez, \& Tulsky, 2003). Although studies demonstrating improved completion of DOPT have been reported among samples of low-income and homeless populations (Tulsky et al., 2004), there are currently no published studies employing a randomized trial of culturally competent TB adherence education and DOPT strategies targeted to homeless adults with LTBI.

The variables of interest in this study emanate from the Comprehensive Health Seeking and Coping Paradigm (CHSCP; Nyamathi, 1989), a theoretical framework that has been used to understand the coping behaviors and health outcomes of impoverished and drug-addicted persons. The model, originally adopted from the Lazarus and Folkman (1984) Stress and Coping Model and the Schlotfeldt (1981) Health Seeking Paradigm, postulates that a number of factors play an influential role in health outcomes and behaviors in vulnerable populations. In this study, key predictive variables from the model include personal factors (depression, dissatisfaction with health care), cognitive factors (TB risk assessment, TB knowledge), situational factors (site of residence), behavioral factors (heroin or cocaine use, alcohol use), and sociodemographic factors (age, gender, education). The nursing intervention takes these factors into account and was designed to affect outcomes of treatment compliance as well as greater knowledge and satisfaction with the treatment experience. This study is the first to use the CHSCP to predict treatment adherence.

Prior research using the CHSCP has demonstrated that depression is associated with higher rates of risky behavior in homeless men and women (Nyamathi, Flaskerud, Keenan, \& Leake, 1998; Nyamathi et al., 2003). Depression has also been associated with poor adherence (Turner, Laine, Cosler, \& Hauck, 2003). It is thought that depressed patients may feel hopeless when the prospect of completing a complex treatment is considered. Perhaps this attitude is related to a perceived lack of self-efficacy, social supports, energy, and memory in carrying out physician recommendations (Wing, Phelan, \& Tate, 2002). Alternatively, positive coping modalities, such as engagement in social support, provide encouragement to the recipient and promote health protection, a sense of belonging, and feelings of personal efficacy (Nyamathi, Leake, Keenan, \& Gelberg, 2000; Nyamathi, Stein, \& Swanson, 2000).

In terms of drug and alcohol use, a clear linkage exists between these substances and poor health care treatment completion ( $R$. Curtis et al., 1994; Pablos-Mendez, Knirsch, Barr, Lerner, \& Frieden, 1997). Persons abusing substances are more likely to have poor access to health care, poor adherence to follow-up visits and prescribed treatment for LTBI, poor nutrition, and limited access to TB education and prevention measures (Francis J. Curry National Tuberculosis Center, Institutional Consultation Services, \& California Department of Health Services, 2000). Moreover, type of residence (street-based vs. shelter-based) has been implicated in risk behavior and mental health profiles of homeless adults (Nyamathi, Leake, \& Gelberg, 2000).

The intervention program in the study reflects the CHSCP in that a strengths-based model of case management was used wherein the personal and social environment of the person was considered and strengthened. Strengths-based features of the intervention program include an emphasis on building effective coping skills, personal assertiveness, self-management, communication, and self-esteem. Attention is given to multiple aspects of the client's health and well-being, including supporting reduction of drug and alcohol use, increasing access to the clinic to enhance treatment completion, and building skills in terms of dealing with psychological distress and personal empowerment.

The purpose of our study was to use structural equation modeling (SEM) to assess predictors of LTBI completion among a sample of 494 homeless adults in Los Angeles, California, who had received a theoretically based intervention program combining nurse case management (NCM), incentives, DOPT, education and skills training, and a tracking protocol versus a usual care control program that included brief education and incentives on completion of a 6-month LTBI chemoprophylaxis treatment with isoniazid (INH).

\section{Method}

\section{Setting and Participants}

Subjects considered for inclusion in the study were homeless adults with LTBI recruited in homeless shelters and residential recovery programs in the Skid Row region of downtown Los Angeles between 1998 and 2003 (Nyamathi et al., 2006). A total of 16 sites were contacted for participation in this study, and 12 ( 8 homeless shelters, 4 residential recovery programs) agreed to participate. Initially, the sites were stratified by type (shelters vs. residential recovery program), typical length of stay ( $<3$ months vs. $\geq 3$ months), and size ( $<130$ beds vs. $\geq 130$ beds). Subsequently, the sites were randomized to the intervention program or standard program. All sites were within 5 miles of the clinic and were fairly equally distributed in terms of distance from the clinic. Intraclass correlations for the study variables were examined on the basis of sites, and all intraclass correlations were extremely small. We did not assess the variables concerned with substance abuse because we expected them to be related to site.

Subjects were eligible to participate in the screening phase of the study if they (a) had spent the previous night in one of the study's homeless shelters; (b) had no self-reported history of completing TB prevention therapy; (c) were between the ages of 18 and 55, or over the age of 55, and reported risk activation factors for active TB, which included IDU, diagnosis of immune compromising diseases (such as severe kidney disease), or taking immunosuppressing medications; and (d) were willing to undergo further diagnostic testing at the John Wesley Community Health Medical Clinic at the Weingart Center in the downtown Los Angeles area and to participate in the intervention study. Inclusion criteria were based on the American Thoracic Society (1990) guidelines for diagnostic standards and classification of TB.

The screening involved a PPD test via the Mantoux method of tuberculin skin testing. Those found to be PPD positive, with a negative chest X-ray and normal liver enzymes, were enrolled in the study. A positive result was defined as having a PPD reaction of $\geq 10 \mathrm{~mm}$ of induration for those not known to be HIV positive; for those who self-reported to be HIV positive, 
$\geq 5 \mathrm{~mm}$ of induration was used. Subjects were excluded from the study if they demonstrated cognitive impairment, such as active hallucinations or stupor. Although cessation or reduction of substance use was encouraged, there was no requirement to abstain from alcohol or drug use.

A total of 3,959 homeless adults was found to be eligible for the screening phase, 5 of whom refused further testing. Of the 3,954 tested, $980(24.8 \%)$ were PPD positive. Of these, 25 refused the chest X-ray, 15 were not eligible for chest X-rays and diagnostic testing, and 199 refused or did not show up for the physician exam. A further 221 participants were not eligible because of active TB $(n=3)$, suspected TB $(n=35)$, refusal to take the medication $(n=26)$, or other medical indicators $(n=157)$, such as abnormal liver function tests $(n=64)$, identification of exclusion factors reported postscreening $(n=73)$, and unstable HIV status $(n=20)$. The resulting sample at baseline consisted of 520 homeless adults. Follow-up data were available for 494 participants (396 men and 98 women), as $5 \%$ of the sample were lost at follow-up. The sample was $82 \%$ African American, 9\% Hispanic, 7\% White, 2\% other, and had a mean age of 41.5 years $(S D=8.5)$; education ranged from 3 to 19 years with a mean of 12 years.

\section{Procedure}

Recruitment procedures consisted of posting fliers outlining the study in the targeted study shelters and residential treatment programs. The fliers directed interested persons to call or visit the research nurses located at a neighborhood clinic within walking distance of the shelters. On selected days, the research nurses visited the research sites and provided a brief description of the study goals and procedures. For interested persons, the research nurses returned to the research sites to conduct the screening procedures of the study. Persons received a detailed description of the study goals and procedures before providing written informed consent as approved by the University of California Human Subjects Protection Committee. Eligible subjects were then engaged in baseline face-to-face interviews lasting $60 \mathrm{~min}$ and conducted in English by trained nurses and outreach workers. During the following 6 months, the intervention was applied according to the study group described below. Monthly liver enzyme testing was conducted to monitor the participants' liver function. At the end of the program (i.e., 6 months after baseline), the follow-up interview lasting $30 \mathrm{~min}$ was conducted. All participants were tracked for completion of the follow-up assessment using a locator guide (Anglin, Hser, \& Booth, 1987) that outlined the places and people who were in contact with the participants. Nurses and outreach workers contacted these references when tracking was necessary. The research nurses and outreach workers who delivered the intervention were not involved in the baseline or follow-up assessments.

\section{Intervention}

The intervention program was designed to enhance completion of a 6-month LTBI treatment regimen in homeless adults. It was conceptually based on the CHSCP (Nyamathi, 1989) as described earlier.

In both the intervention and control programs, homeless adults were asked to attend the research clinic twice a week over a period of 6 months to receive the INH dose (900 $\mathrm{mg}$ of INH and $50 \mathrm{mg}$ of Vitamin B6). INH was administered by research nurses by direct observation. Each participant was provided a 10-min question and answer session regarding LTBI treatment before receiving the INH dose. During each session, time was devoted to individualized needs, such as referral to treatments or services. All participants were also given a detailed directory of community resources and services of local agencies. Incentives of $\$ 5$ were paid to the participant for each dose of INH received. In addition, participants in the control program received a single 20-min factual presentation on TB and the importance of being compliant with the LTBI treatment. Participants requesting assistance with non-TB health care problems were referred to the medical clinic located on site.
The core difference between the intervention and control program was the NCM program and tracking protocol. Participants in the intervention program attended a comprehensive educational and skills training module comprising eight 1-hr sessions across the 6-month regimen with four to five participants at a time. A total of $78 \%$ of the participants completed all eight intervention sessions, and the remainder completed at least two sessions. The program was delivered by research nurses and outreach workers in a culturally competent and tailored manner, that is, it used language familiar to the recipients and visual messages, it was delivered by educators of similar ethnicity, and educators themselves were at ease with drug and sexual topics. Intervention components included (a) changing context activities related to self-esteem, future-oriented planning, and attitudinal readiness for change; (b) TB and HIV risk reduction education; (c) training in coping, self-management, and communication skills; (d) training in social and cognitive problem solving to implement behavior change; and (e) developing relationships and social networks to maintain behavior change. Intervention techniques included factual presentations, group discussions, role playing, presentations of culturally sensitive pictorial coping scenarios (Nyamathi \& Bennett, 1997), as well as behavioral exercises and demonstrations. In addition, participants who missed appointments for the INH dose or the NCM program were actively tracked and reengaged in the program by the outreach staff using the detailed locator guides.

The research nurses and outreach workers received special training as extended care providers to ensure optimal skills in providing the intervention. The training was performed by the investigators; outside experts in the areas of TB, HIV, and interaction with homeless adults; as well as behavioral scientists with expertise regarding treatment compliance. Process evaluation was maintained by the investigators to ensure rigor of the study.

\section{Measures}

Multiple-indicator latent variables were created from assessment items as described below. Latent variables are error-free constructs that represent a higher order of abstraction than measured variables. Latent variables allow correlations or simultaneous equations relations among unobserved but hypothesized unmeasured variables, with indicators of these latent variables serving as a factor analysis type of measurement model. Several control, group membership, and demographic variables are single-indicator items and are also described below. All baseline items were conceptualized as possible influences on the outcome variables.

\section{Baseline Predictors}

Site type. Whether the participant's residential site type was a homeless shelter or a residential treatment program could have had an impact on the outcomes of interest in this study. Site type was related to other predictors as well so it was necessary as a control variable. Site type was included as a dichotomous variable $(1=$ homeless shelter; $2=$ residential substance abuse facility).

Sociodemographics. Age was included as a covariate of the other predictors and as a predictor of the outcome variables. Age was a continuous variable indicating the participant's age in years. Gender, ethnicity, and education were initially included in preliminary analyses but were not associated with any of the outcomes. Thus, these variables were eliminated from the analysis.

Intervention status. The critical group membership variable in this study was participation in the NCM and incentive condition versus the usual care plus incentive condition. NCM was coded 1 , usual care was coded $0 ; 54 \%$ of the sample was in the NCM condition.

Dissatisfaction with health care. A latent variable comprised three parcels of means created from eight items assessing participants' dissatisfaction with their health care providers in the past. We combined items to avoid too many indicators of this latent variable (Little, Cunningham, 
Shahar, \& Widaman, 2002). This is an acceptable method when the coefficient alpha among all of the items is high (in this case, $\alpha=.83$ ) and no clear factor structure can separate the items into meaningful subfactors (first eigenvalue $=4.3$; Yuan, Bentler, \& Kano, 1997). Items were on a 4-point scale ranging from 1 (strongly agree) to 4 (strongly disagree); typical items included "In the past, I have been very satisfied with the health care I have received" and "In the past, I have had difficulty making an appointment to see a doctor or nurse." Items were reverse-scored where appropriate.

Depression. Depression was assessed with the Center for Epidemiological Studies-Depression Scale (CES-D; Radloff, 1977). The 20-item, self-report instrument is designed to measure depressive symptomatology in the general population and has been validated for use in homeless populations (Ritchey, La Gory, Fitzpatrick, \& Mullis, 1990). Each item measures the frequency of a symptom on a 4-point response scale ranging from 0 (rarely or none of the time; less than 1 day) to 3 (most of the time; 5-7 days). Examples of CES-D items are "I felt depressed" and "I felt fearful." Because of the high coefficient alpha among the items (.85), we collapsed the items into four parcels of 5 items each using the same parceling technique as described above.

$T B$ risk assessment. This latent variable was indicated by three items. All were scaled from 1 to 4: (a) "Do you think your chances of getting tuberculosis are high, medium, low, no chance?" (b) "Is preventing tuberculosis easy, somewhat difficult, very difficult, impossible?" and (c) "If you don't complete your treatment for TB, your risk of getting TB in the future will be very high, moderately high, low, nonexistent." Items were rescaled so that higher values indicated greater perception of risk.

Alcohol use. This variable was indicated by three items: (a) alcohol frequency in the past 6 months ranging from 1 (never) to 9 (4 or more times per day), (b) number of drinks per day on a typical day ranging from 1 ( 1 or 2) to 5 (10 or more), and (c) the mean of responses to the four-item CAGE screener (Ewing, 1984). CAGE questions assess whether the individual has ever tried "cutting down" on drinking, has ever been "annoyed by criticism" regarding drinking, felt "guilty about drinking," or needed an "eye opener" in the morning. Coefficient alpha for the CAGE instrument in this sample was .81 .

Heroin or cocaine use. This latent construct was indicated with three items: (a) cocaine frequency, (b) heroin mixed with cocaine frequency (e.g., speedballs), and (c) heroin frequency. All were assessed in a manner similar to that reported above for alcohol frequency (1-9 scale).

$T B$ knowledge. This was a single item reporting the participant's score on a 13-item TB knowledge questionnaire. Typical items included "TB cannot be spread by coughing, sneezing, or spitting" and "TB disease can severely damage a person's lungs."

\section{6-Month Outcomes}

Completed treatment. This is a dichotomous variable that reports whether the participant completed treatment $(1=$ no; $2=$ yes $) ; 54 \%$ were reported as having completed treatment. Completion was defined as $100 \%$ compliance with the INH treatment regimen.

$T B$ knowledge. This was the same single item sum score variable described above for baseline TB knowledge that was assessed at the 6-month follow-up assessment.

Ease of treatment. This latent variable was assessed with three items that indicated how difficult the participant found the treatment regimen. Items 1 and 2 were assessed on a 4-point scale ranging from 1 (very hard) to 4 (very easy). They were worded as follows: "Now that your participation with taking INH (isoniazid) is over, how easy or hard was it to (a) take the INH as recommended and (b) keep the follow-up appointments that were scheduled?" The third item asked whether they had to take time off from doing other things when they came to the clinic appointments and was assessed on a 3-point scale ranging from 1 (Yes, always or almost always) to 3 (No, I was able to schedule clinic appointments around my activities).

Depression. Depression was assessed in the same way as at baseline.
Dissatisfaction with treatment. This latent variable was related to participants' specific experience with INH treatment and was not analogous to their past general dissatisfaction with health care described above, which was a predictor in this model. This scale was based on 12 items that were scored from 1 (strongly agree) to 4 (strongly disagree). Typical items include "I am very satisfied with the care I received from the nurse at the TB clinic" and "I felt the nurse listened to and understood my concerns." Items were reverse-scored if appropriate. Three parcels were constructed for this construct because of their high coefficient alpha (.81) and large first eigenvalue (4.1).

\section{Analyses}

The analytic method selected for this study was SEM using latent variables (Bentler, 2005). Latent variables are error-free constructs that provide an order of abstraction superior to that of measured variables and represent the shared variance among multiple measured variables. The goodness of fit of the model was assessed with the Satorra-Bentler chisquare ( $\mathrm{S}-\mathrm{B} \chi^{2}$ ), the robust comparative fit index (RCFI), and the rootmean-squared error of approximation (RMSEA; Hu \& Bentler, 1999). The S-B $\chi^{2}$ was used because the data were multivariately kurtose (Bentler \& Dudgeon, 1996). The RCFI ranges from 0 to 1 and reflects the improvement in fit of a hypothesized model over a model of complete independence among the measured variables and also adjusts for sample size (Bentler \& Dudgeon, 1996). Values at around .95 or greater are desirable for the RCFI, and a cutoff value close to or less than .06 for the RMSEA is also desirable (Hu \& Bentler, 1999).

\section{Confirmatory Factor Analyses (CFA)}

Initial CFAs were performed with each latent construct predicting its hypothesized manifest indicators. All latent constructs and the single-item variables were correlated without any assumption of causality among them. This analysis tested the sufficiency of the measurement model and measured associations among the latent and measured variables. The Lagrange multiplier test, which suggests additional relationships to add to models for fit improvement, was used to determine whether any supplementary paths were needed (Chou \& Bentler, 1990).

\section{Latent Variable Path Analysis}

A predictive structural equation path model positioned site type, age, type of intervention, prior dissatisfaction with health care, depression, TB risk assessment, alcohol use, heroin or cocaine use, and TB knowledge as the baseline predictors. They predicted the follow-up outcome variables of treatment completion, TB knowledge, ease of treatment, depression, and dissatisfaction with treatment.

\section{Results}

\section{$C F A$}

Fit indexes for the CFA model testing the adequacy of the measurement model were quite acceptable: S-B $\chi^{2}(378, N=$ $494)=575.13$, RCFI $=.96$, RMSEA $=.033$. Only one supplementary covariance between the error residuals of heroin and heroin or cocaine use was added to this model. This nonhypothesized relationship appears to be quite reasonable. In addition, all measured variables loaded significantly $(p<.001)$ on their hypothesized latent factors. Table 1 presents the factor loadings of the measured variables on their hypothesized latent variables for the CFA model and the means and standard deviations of the measured variables. 
Table 1

Means, Standard Deviations, and Factor Loadings in the Confirmatory Factor Analysis

\begin{tabular}{|c|c|c|c|}
\hline Variable & $M$ & $S D$ & $\begin{array}{l}\text { Factor } \\
\text { loading }\end{array}$ \\
\hline \multicolumn{4}{|l|}{ Baseline } \\
\hline $\begin{array}{l}\text { 1. Site type } \\
\begin{array}{l}1=\text { homeless shelter } \\
2=\text { recovery shelter }\end{array}\end{array}$ & 1.21 & 0.41 & \\
\hline 2. Age (years) & 41.54 & 8.52 & \\
\hline $\begin{array}{l}\text { 3. Nurse-managed intervention }(0=\text { no; } 1=\text { yes }) \\
\text { 4. Dissatisfaction with health care }\end{array}$ & 0.54 & 0.50 & \\
\hline Parcel 1 & 1.90 & 0.59 & .78 \\
\hline Parcel 2 & 1.83 & 0.58 & .87 \\
\hline Parcel 3 & 1.62 & 0.67 & .69 \\
\hline 5. Depression & & & \\
\hline CES-D (Parcel 1) & 1.71 & 0.58 & .79 \\
\hline CES-D (Parcel 2) & 1.80 & 0.69 & .80 \\
\hline CES-D (Parcel 3) & 2.03 & 0.65 & .80 \\
\hline CES-D (Parcel 4) & 1.64 & 0.61 & .81 \\
\hline 6. TB risk assessment & & & \\
\hline Chances of contracting TB & 2.18 & 0.97 & .44 \\
\hline Ease of preventing & 2.05 & 1.11 & .45 \\
\hline Future risk & 1.50 & 0.83 & .69 \\
\hline 7. Alcohol use & & & \\
\hline Frequency & 3.47 & 2.98 & .74 \\
\hline Number drinks/day & 1.61 & 1.53 & .87 \\
\hline CAGE screener & 1.66 & 1.55 & .44 \\
\hline 8. Heroin or cocaine use & & & \\
\hline Cocaine frequency & 0.74 & 2.08 & .41 \\
\hline Heroin and cocaine mix frequency & 0.19 & 1.08 & .67 \\
\hline Heroin frequency & 0.38 & 1.57 & .55 \\
\hline 9. TB knowledge & 7.45 & 3.17 & \\
\hline
\end{tabular}

6-month outcome

$\begin{array}{lrrr}\text { 10. Completed treatment }(1=\text { no; } 2=\text { yes }) & 1.54 & 0.50 & \\ \text { 11. TB knowledge } & 10.45 & 2.52 & \\ \text { 12. Ease of treatment } & & & \\ \text { Taking INH } & 3.32 & 1.03 & .83 \\ \text { Keeping appointments } & 3.15 & 1.13 & .92 \\ \text { Schedule around activities } & 2.34 & 0.78 & .71 \\ \text { 13. Depression (follow-up) } & & & \\ \text { CES-D (Parcel 1) } & 1.67 & 0.57 & .80 \\ \text { CES-D (Parcel 2) } & 1.69 & 0.60 & .79 \\ \text { CES-D (Parcel 3) } & 1.86 & 0.60 & .81 \\ \text { CES-D (Parcel 4) } & 1.53 & 0.58 & .83 \\ \text { 14. Dissatisfaction with treatment } & & & \\ \text { Parcel 1 } & 1.13 & 0.32 & .68 \\ \text { Parcel 2 } & 1.18 & 0.37 & .75 \\ \text { Parcel 3 } & 1.11 & 0.26 & .74\end{array}$

Note. All factor loadings are significant $(p<.001)$. Dissatisfaction with health care was scored on the basis of 3 parcels of means created from 8 items of prior health care dissatisfaction; CES-D Depression was scored on the basis of 4 parcels of 5 items each; Dissatisfaction with treatment was scored on the basis of 3 parcels (see Method section). CES-D = Center for Epidemiological Studies-Depression Scale; $\mathrm{TB}=$ active tuberculosis; INH $=$ isoniazid.

Table 2 presents the correlations among the latent variables and the measured variables. Of particular note in the CFA model, treatment completion was significantly associated with having been a participant in the NCM intervention $(r=.22, p<.001)$. Sixty-four percent of those in the NCM condition completed their LTBI treatment; $42 \%$ of those in the standard care condition completed LTBI treatment. Other significant correlates of completion included homeless shelter residence, older age, less alcohol and heroin or cocaine use, greater ease of treatment, less depression at 6-month follow-up, less dissatisfaction with treatment, and more TB knowledge at follow-up. Significant correlates of the NCM intervention included homeless shelter residence at baseline, greater risk assessment, greater ease of treatment, considerably less dissatisfaction with treatment, and greater TB knowledge at follow-up. It is worth noting that the association with TB knowledge was nonsignificant at baseline. At baseline, the mean knowledge scores were 7.3 and 7.6 for the standard care and NCM groups, respectively $(p>.05)$. At follow-up, mean knowledge scores were 9.3 for standard care and 11.4 for $\mathrm{NCM}(p<.001)$.

\section{Path Analysis}

Figure 1 presents the final trimmed path model that includes the correlations among the predictors and correlations among the residuals of the outcome variables. It has excellent goodness-of-fit statistics: $\mathrm{S}-\mathrm{B} \chi^{2}(442, N=494)=619.62$, RCFI $=.96$, RMSEA $=.029$. Treatment completion was predicted by participation in the NCM intervention, older age, and less heroin or cocaine use. Site type was not a predictor of treatment completion despite the fact that randomization did not yield a perfectly balanced site application. The NCM intervention also had other positive outcomes: It predicted greater TB knowledge, greater ease of treatment, and less dissatisfaction with treatment. Depression was found to be the major and only predictor of depression at follow-up. Depressive affect did not predict treatment completion. A serious drug abuse problem as typified by heroin and/or cocaine use did have a significant although modest effect on treatment completion. The initial bivariate association between alcohol use and completion was not significant in the path model. A prior history of general dissatisfaction with health care did not predict dissatisfaction with TB care.

\section{Discussion}

Findings of our site-randomized study revealed that participants in the NCM program were significantly more likely to complete LTBI treatment than were participants in the usual care control program. Despite the fact that LTBI treatment is an especially arduous process, requiring $100 \%$ adherence to a 6-month regimen, our intervention program was able to induce and maintain a long-term commitment in this difficult to manage population. In addition, preexisting attitudes, behaviors, and psychosocial problems did not affect completion of the regimen. This result is especially important in this difficult and impoverished population whose members bring so many coexisting problems with them when they enter treatment. For instance, greater depression, alcohol use, and prior negative attitudes about health care did not predict less treatment completion.

Participants in the NCM program also reported higher TB knowledge, greater ease of treatment, and less dissatisfaction with treatment. Treatment completion might be viewed as a principal behavioral outcome of the intervention. Greater TB knowledge after the intensive intervention captures cognitive aspects and ease of treatment, and satisfaction with treatment captures psychological, emotional, or affective characteristics. In this regard, the 
Table 2

Correlations Among Latent and Measured Variables

\begin{tabular}{|c|c|c|c|c|c|c|c|c|c|c|c|c|c|}
\hline Variable & 1 & 2 & 3 & 4 & 5 & 6 & 7 & 8 & 9 & 10 & 11 & 12 & 13 \\
\hline \multicolumn{14}{|c|}{ Baseline } \\
\hline $\begin{array}{l}\text { 1. Site type }=\text { recovery } \\
\text { 2. Age (years) } \\
\text { 3. Nurse intervention } \\
\text { 4. Dissatisfaction with health care } \\
\text { 5. Depression } \\
\text { 6. TB risk assessment } \\
\text { 7. Alcohol use } \\
\text { 8. Heroin or cocaine use } \\
\text { 9. TB knowledge }\end{array}$ & $\begin{array}{l}-\overline{14^{* *}} \\
-.30^{* * * *} \\
.06 \\
.14^{* *} \\
-.04 \\
.20^{* * *} \\
.23^{* * *} \\
-.02\end{array}$ & $\begin{aligned} &- \\
& .04 \\
&-.10^{*} \\
&-.06 \\
& .08 \\
&-.02 \\
&-.03 \\
& .09^{*}\end{aligned}$ & $\begin{array}{r}-\overline{-08} \\
-.06 \\
.13^{*} \\
-.03 \\
-.06 \\
.04\end{array}$ & $\begin{array}{l}\overline{-} 7^{* * * *} \\
-.25^{* * *} \\
.08 \\
.10 \\
-.16^{* * *}\end{array}$ & $\begin{array}{c}-\overline{-}^{\text {*** }} \\
-.23^{* * *} \\
.13^{* *} \\
-.08\end{array}$ & $\begin{array}{r}-\overline{.00} \\
-.02 \\
-.17^{* * * *}\end{array}$ & $\begin{array}{c}-14^{*} \\
-.02\end{array}$ & $\overline{.01}$ & - & & & & \\
\hline \multicolumn{14}{|c|}{ 6-month outcome } \\
\hline $\begin{array}{l}\text { 10. Completed treatment } \\
\text { 11. Ease of treatment } \\
\text { 12. Depression } \\
\text { 13. Dissatisfaction with treatment } \\
\text { 14. TB knowledge }\end{array}$ & $\begin{array}{l}-.14^{* *} \\
-.04 \\
-.00 \\
.12^{*} \\
-.09^{*}\end{array}$ & $\begin{aligned} & .12^{* * *} \\
& . 13^{* * *} \\
&-.04 \\
&-.02 \\
& .04\end{aligned}$ & $\begin{aligned} & .22^{* * * *} \\
. & 11^{*} \\
- & .06 \\
- & .27^{* * *} \\
& .41^{* * *}\end{aligned}$ & $\begin{array}{l}-.08 \\
-.15^{* *} \\
.15^{* *} \\
-.05 \\
.01\end{array}$ & $\begin{array}{l}-.01 \\
-.02 \\
.40^{* * *} \\
.03 \\
-.07\end{array}$ & $\begin{array}{r}.03 \\
.04 \\
-.13^{*} \\
.02 \\
.03\end{array}$ & $\begin{array}{l}-.11^{*} \\
-.06 \\
.11^{*} \\
.01 \\
-.02\end{array}$ & $\begin{array}{l}-.17^{\text {*** }} \\
-.05 \\
.07 \\
.06 \\
-.16^{\text {** }}\end{array}$ & $\begin{array}{r}.04 \\
.02 \\
-.01 \\
.08 \\
.04\end{array}$ & $\begin{aligned} & -65^{* * *} \\
- & .10^{*} \\
- & .11^{*} \\
. & 14^{\mathrm{b}}\end{aligned}$ & $\begin{array}{c}\overline{1}^{\text {*** }} \\
-.22^{* * *} \\
.14^{* *}\end{array}$ & $\begin{array}{r}\overline{-}^{\text {*** }} \\
-.07\end{array}$ &.$- \overline{36}^{* * *}$ \\
\hline
\end{tabular}

${ }^{*} p<.05 .{ }^{* * *} p<.01 .{ }^{* * *} p<.001$.

intervention significantly improved a variety of different outcome variables, thus supporting the broader CHSCP theoretical framework that proposes coping as a central concept. Homeless adults in particular deal with numerous constraints with which they must cope. Specifically, these include lack of housing and personal barriers, such as depression, and lack of resources, such as financial support. Successful coping results in attempts to overcome barriers, which result in optimum outcomes. Thus, the CHSCP result is a very useful framework for nurses interested in enhancing or promoting the health seeking and coping of vulnerable clients. This framework has also previously demonstrated the impact of other theoretically based nursing programs targeted to reduce HIV risk activities among homeless and drug-using minority women (Nyamathi, Leake, Flaskerud, Lewis, \& Bennett, 1993; Nyamathi \& Stein, 1997; Stein, Nyamathi, \& Kington, 1997). The current study successfully extends previous work to the area of TB treatment. Thus, our intervention may represent a portable program for increasing compliance that can be adapted to various difficult populations and a variety of treatment areas.

Central for LTBI treatment completion was the inclusion of comprehensive culturally competent NCM and tracking. It has long been recognized that high-risk populations need special strategies to ensure adequate treatment (CDC, 2000; Joint Tuberculosis Committee of the British Thoracic Society, 2000). The findings of our study suggest that NCM educational and skills training may be crucial components contributing to the long-term management of TB in the United States, thus strengthening the goal for the worldwide elimination of TB (CDC, 1995; Geiter, 2000).

We acknowledge that we employed a comprehensive, detailed intervention program. Although cost-effectiveness data for our program are not available, high cost intensity can be assumed because of the individual care by nurses, as well as the timeconsuming tracking protocol. However, the benefits associated with LTBI treatment completion may well outweigh the costs of the intervention program. Completing the LTBI treatment will decrease the risk of conversion to active TB, reduce further spread of the disease, and reduce the subsequent psychological sequelae, as well as the significant morbidity and mortality associated with this disease.

The modeling approach enabled control for potentially confounding variables. We included a number of variables that are well known to impede intervention effects, such as depressive symptomatology, substance use (R. Curtis et al., 1994), and older age (Morisky et al., 2001). However, findings revealed that the strongest predictor for treatment completion was membership in the intervention program, even after accounting for other significant predictors. In addition, older age and less heroin or cocaine use predicted treatment completion.

Several significant correlations among the baseline variables warrant mentioning. Although site type was correlated with the intervention program, indicating that the intervention was more available in homeless shelters than in residential recovery programs, treatment completion did not differ as a function of site type but rather as a function of age and substance use. Thus, despite these preexisting differences, treatment completion and the other main outcome variables were still mainly predicted by membership in the intervention program. Furthermore, TB knowledge at baseline did not predict any of the outcome measures, including TB knowledge at follow-up. This is surprising given that in longitudinal applications of SEM, a construct over time tends to be predicted strongly by the preceding same construct. Here, however, no direct path was established; instead, TB knowledge at follow-up was strongly predicted by the NCM intervention and to a lesser extent by heroin or cocaine use. Thus, irrespective of preexisting TB knowledge, membership in the intervention program resulted in higher TB knowledge. This finding indicates great success of the intervention program with respect to TB education.

The setting was a limited number of homeless shelters and residential recovery programs in downtown Los Angeles. The sample may not be representative of homeless individuals in other 


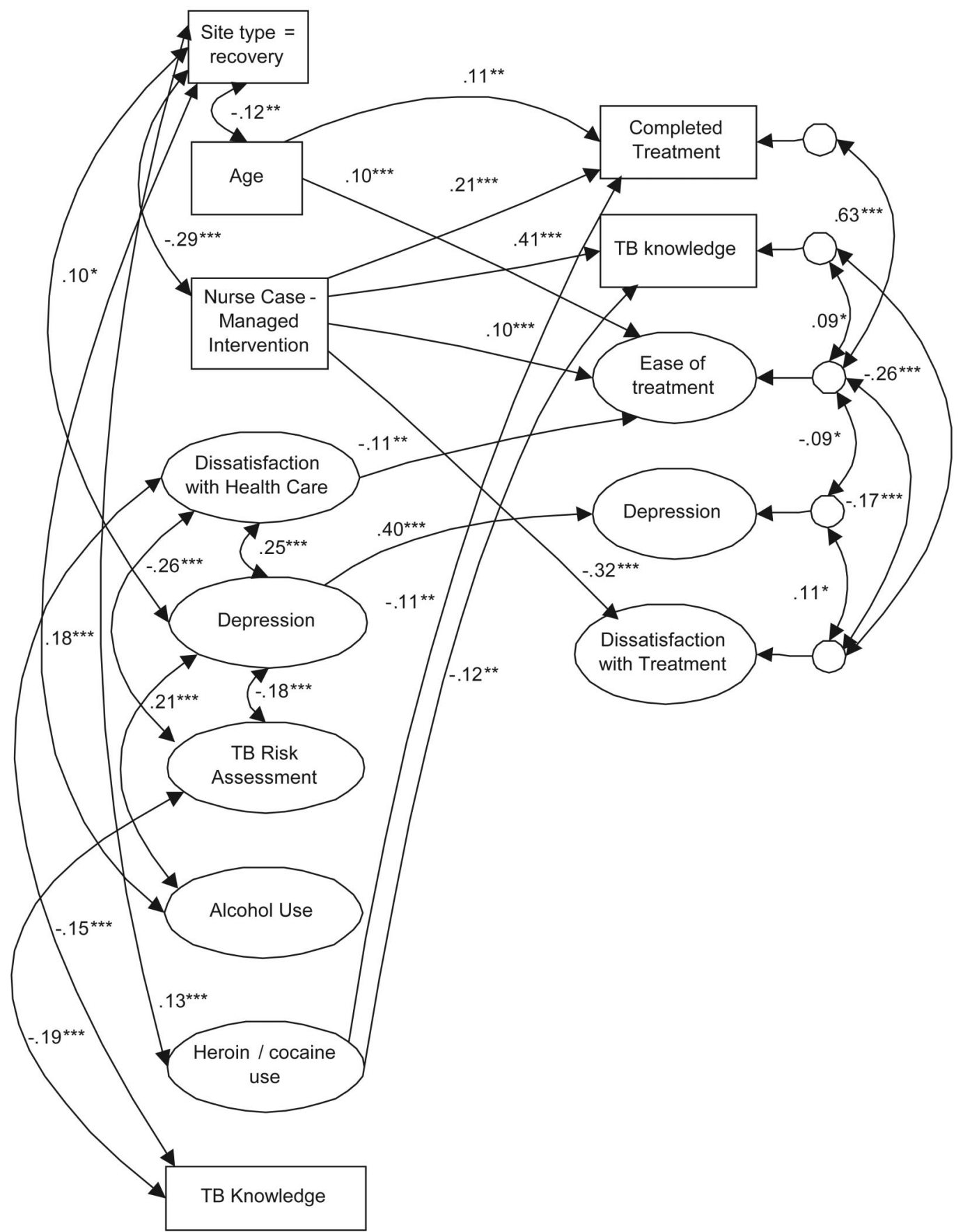

Figure 1. Final structural path model. All estimated parameters are standardized. The large circles designate latent variables; the rectangles represent measured variables. One-headed arrows represent regression paths, two-headed arrows represent correlations. Small circles represent error residuals of predicted variables. TB $=$ active tuberculosis ${ }^{*} p<.05 .{ }^{* * *} p<.01 .{ }^{* * * *} p<.001$.

parts of the country, thus lessening the generalizability of the findings. The assessment of drug and alcohol use relied on selfreports only. However, we have found strong correlations between objective measures of substance use and self-report data in previ- ous studies (Nyamathi, Leake, Longshore, \& Gelberg, 2001). Finally, limiting persons with high liver function tests may have resulted in a biased outcome as these persons may be at high risk for active TB. 
In summary, we conclude that an intervention program providing NCM and tracking combined with cultural sensitivity has influenced LTBI treatment completion among homeless adults. The findings encourage the provision of comprehensive intervention programs that consider and acknowledge the specific needs of this population. In an effort to promote cost-effective programs, researchers should focus on assessing cost effectiveness of programs provided. Furthermore, researchers need to determine whether there are subgroups of high-risk individuals who respond to streamlined versions of the more intense and comprehensively detailed programs.

\section{References}

American Thoracic Society. (1990). Diagnostic standards and classification of tuberculosis. American Review of Respiratory Diseases, 142, 725-735.

Anglin, M. D., Hser, Y., \& Booth, M. W. (1987). Sex differences in addict careers: Treatment. American Journal of Drug and Alcohol Abuse, 13, 253-280.

Asch, S., Leake, B., Knowles, L., \& Gelberg, L. (1998). Tuberculosis in homeless patients: Potential for case finding in public emergency departments. Annals of Emergency Medicine, 32, 144-147.

Bentler, P. M. (2005). EQS 6 structural equations program manual. Encino, CA: Multivariate Software, Inc.

Bentler, P. M., \& Dudgeon, P. (1996). Covariance structure analysis: Statistical practice, theory, and directions. Annual Review of Psychology, $47,563-592$.

Centers for Disease Control and Prevention. (1995). Essential components of a tuberculosis prevention and control program: Recommendations of the Advisory Council for the Elimination of Tuberculosis. Morbidity and Mortality Weekly Report, 44, 1-16.

Centers for Disease Control and Prevention. (2000). Targeted tuberculin testing and treatment of latent tuberculosis infection. Morbidity and Mortality Weekly Report, 49, 1-54.

Centers for Disease Control and Prevention. (2004). Trends in tuberculosis; United States, 1998-2003. Morbidity and Mortality Weekly Report, 53, 209-214.

Cheung, R. C., Hanson, A. K., Maganti, K., Keeffe, E. B., \& Matsui, S. M. (2002). Viral hepatitis and other infectious diseases in a homeless population. Journal of Clinical Gastroenterology, 34, 476-480.

Chou, C.-P., \& Bentler, P. M. (1990). Model modification in covariance structure modeling: A comparison among likelihood ratio, Lagrange Multiplier, and Wald tests. Multivariate Behavioral Research, 25, 115136

Curtis, A. B., Ridzon, R., Novick, L. F., Driscoll, J., Blair, D., Oxtoby, M., et al. (2000). Analysis of Mycobacterium tuberculosis transmission patterns in a homeless shelter outbreak. International Journal of Tuberculosis and Lung Disease, 4, 308-313.

Curtis, R., Friedman, S. R., Neaigus, A., Jose, B., Goldstein, M., \& Des Jarlais, D. C. (1994). Implications of directly observed therapy in tuberculosis control measures among IDUs. Public Health Reports, 109, 319-327.

Daley, C. L., Hahn, J. A., Moss, A. R., Hopewell, P. C., \& Schecter, G. F. (1998). Incidence of tuberculosis in injection drug users in San Francisco: Impact of anergy. American Journal of Respiratory and Critical Care Medicine, 157, 19-22.

Ewing, J. A. (1984). Detecting alcoholism: The CAGE questionnaire. Journal of the American Medical Association, 252, 1905-1907.

Forman, P. D., \& Kinney, C. (2003). Evaluation of a tuberculosis screening questionnaire for use in an Alaskan homeless population. Alaska Medicine, 45, 94-101.

Francis J. Curry National Tuberculosis Center, Institutional Consultation
Services, \& California Department of Health Services. (2000). TB in homeless shelters: Reducing the risk through ventilation, filters and UV. San Francisco: Author.

Gallagher, T. C., Andersen, R. M., Koegel, P., \& Gelberg, L. (1997). Determinants of regular source of care among homeless adults in Los Angeles. Medical Care, 35, 814-830.

Geiter, L. (Ed.). (2000). Ending neglect: The elimination of tuberculosis in the United States. Washington, DC: National Academies Press.

Gelberg, L., Andersen, R. M., \& Leake, B. D. (2000). The behavioral model for vulnerable populations: Application to medical care use and outcomes for homeless people. Health Services Research, 34, 12731302.

Gelberg, L., Panarites, C. J., Morgenstern, H., Leake, B., Anderson, R. M., \& Koegel, P. (1997). Tuberculosis skin testing among homeless adults. Journal of General Internal Medicine, 12, 25-33.

Griffin, R. G., \& Hoff, G. L. (1999). Tuberculosis screening in Kansas City homeless shelters. Missouri Medicine, 96, 496-499.

Hageman, J. R. (1998). Congenital and perinatal tuberculosis: Discussion of difficult issues in diagnosis and management. Journal of Perinatology, 18, 389-394.

Herndon, B., Asch, S. M., Kilbourne, A. M., Wang, M. M., Lee, M., Wenzel, S. L., et al. (2003). Prevalence and predictors of HIV testing among a probability sample of homeless women in Los Angeles County. Public Health Reports, 118, 261-269.

Hu, L. T., \& Bentler, P. M. (1999). Cutoff criteria for fit indexes in covariance structure analysis: Conventional criteria versus new alternatives. Structural Equation Modeling, 6, 1-55.

Jasmer, R. M., Nahid, P., \& Hopewell, P. C. (2002). Clinical practice. Latent tuberculosis infection. New England Journal of Medicine, 347, $1860-1866$

Joint Tuberculosis Committee of the British Thoracic Society. (2000). Control and prevention of tuberculosis in the United Kingdom: Code of practice 2000. Thorax, 55, 887-901.

Kimerling, M. E., Shakes, C. F., Carlisle, R., Lok, K. H., Benjamin, W. H., \& Dunlap, N. E. (1999). Spot sputum screening: Evaluation of an intervention in two homeless shelters. International Journal of Tuberculosis and Lung Disease, 3, 613-619.

Lazarus, R., \& Folkman, S. (1984). Stress, appraisal and coping. New York: Springer.

Little, T. D., Cunningham, W. A., Shahar, G., \& Widaman, K. F. (2002). To parcel or not to parcel: Exploring the question, weighing the merits. Structural Equation Modeling, 9, 151-173.

Morisky, D. E., Malotte, C. K., Ebin, V., Davidson, P., Cabrera, D., Trout, P. T., \& Coly, A. (2001). Behavioral interventions for the control of tuberculosis among adolescents. Public Health Reports, 116, 568-574.

Moss, A. R., Hahn, J. A., Perry, S., Charlebois, E. D., Guzman, D., Clark, R. A., \& Bangsberg, D. R. (2004). Adherence to highly active antiretroviral therapy in the homeless population in San Francisco: A prospective study. Clinical Infectious Diseases, 39, 1190-1198.

Moss, A. R., Hahn, J. A., Tulsky, J. P., Daley, C. L., Small, P. M., \& Hopewell, P. C. (2000). Tuberculosis in the homeless. A prospective study. American Journal of Respiratory and Critical Care Medicine, $162,460-464$.

Munch, Z., Van Lill, S. W., Booysen, C. N., Zietsman, H. L., Enarson, D. A., \& Beyers, N. (2003). Tuberculosis transmission patterns in a high-incidence area: A spatial analysis. International Journal of Tuberculosis and Lung Disease, 7, 271-277.

Nardell, E., McInnis, B., Thomas, B., \& Weidhaas, S. (1986). Exogenous reinfection with tuberculosis in a shelter for the homeless. New England Journal of Medicine, 315, 1570-1575.

Nazar-Stewart, V., \& Nolan, C. M. (1992). Results of a directly observed intermittent isoniazid preventive therapy program in a shelter for homeless men. American Review of Respiratory Diseases, 146, 57-60. 
Nyamathi, A. (1989). Comprehensive health seeking and coping paradigm. Journal of Advanced Nursing, 14, 281-290.

Nyamathi, A., \& Bennett, C. (1997). Visual coping scenarios to facilitate discussion of coping responses with impoverished women at risk for AIDS. Journal of Psychosocial Nursing and Mental Health Services, 35, $17-23$.

Nyamathi, A., Christiani, A., Nahid, P., Strehlow, A., Gregerson, P., Morisky, D., \& Leake, B. (2006). A randomized controlled trial of two treatment programs for homeless adults with latent tuberculosis infection. International Journal of Tuberculosis and Lung Disease, 10, 775782.

Nyamathi, A., Flaskerud, J., Keenan, C., \& Leake, B. (1998). Effectiveness of a specialized vs. traditional AIDS education program attended by homeless and drug-addicted women alone or with supportive persons. AIDS Education and Prevention, 10, 433-446.

Nyamathi, A., Keenan, C., \& Bayley, L. (1998). Differences in personal, cognitive, psychological, and social factors associated with drug and alcohol use and nonuse by homeless women. Research in Nursing \& Health, 21, 525-532.

Nyamathi, A., Leake, B., Flaskerud, J., Lewis, C., \& Bennett, C. (1993). Outcomes of specialized and traditional AIDS counseling programs for impoverished women of color. Research in Nursing \& Health, 16, $11-21$.

Nyamathi, A., Leake, B., Keenan, C., \& Gelberg, L. (2000). Type of social support among homeless women: Its impact on psychosocial resources, health and health behaviors, and use of health services. Nursing Research, 49, 318-326.

Nyamathi, A., Leake, B., Longshore, D., \& Gelberg, L. (2001). Reliability of homeless women's reports: Concordance between hair assay and self-report of cocaine use. Nursing Research, 50, 165-171.

Nyamathi, A., \& Shuler, P. (1990). Focus group interview: A research technique for informed nursing practice. Journal of Advanced Nursing, $15,1281-1288$

Nyamathi, A., \& Stein, J. (1997). Assessing the impact of HIV risk reduction counseling in impoverished African American women: A structural equations approach. AIDS Education and Prevention, 9, 253273.

Nyamathi, A. M., Leake, B., \& Gelberg, L. (2000). Sheltered versus nonsheltered homeless women differences in health, behavior, victimization, and utilization of care. Journal of General Internal Medicine, $15,565-572$.

Nyamathi, A. M., Stein, J. A., Dixon, E., Longshore, D., \& Galaif, E. (2003). Predicting positive attitudes about quitting drug and alcohol use among homeless women. Psychology of Addictive Behaviors, 17, 32-41.

Nyamathi, A. M., Stein, J. A., \& Swanson, J. M. (2000). Personal, cognitive, behavioral, and demographic predictors of HIV testing and STDs in homeless women. Journal of Behavioral Medicine, 23, 123-147.

Pablos-Mendez, A., Knirsch, C. A., Barr, R. G., Lerner, B. H., \& Frieden,
T. R. (1997). Nonadherence in tuberculosis treatment: Predictors and consequences in New York City. American Journal of Medicine, 102, $164-170$.

Radloff, L. (1977). The CES-D scale: A self-report depression scale for research in the general population. Applied Psychological Measurement, 1, 385-401.

Ritchey, F. J., La Gory, M., Fitzpatrick, K. M., \& Mullis, J. (1990). A comparison of homeless, community-wide, and selected distressed samples on the CES-Depression Scale. American Journal of Public Health, 80, 1384-1386.

Schlotfeldt, R. M. (1981). Nursing in the future. Nursing Outlook, 29, 295-301.

Selwyn, P. A., Hartel, D., Lewis, V. A., Schoenbaum, E. E., Vermund, S. H., Klein, R. S., et al. (1989). A prospective study of the risk of tuberculosis among intravenous drug users with human immunodeficiency virus infection. New England Journal of Medicine, 320, 545-550.

Small, P. M., \& Fujiwara, P. I. (2001). Management of tuberculosis in the United States. New England Journal of Medicine, 345, 189-200.

Stein, J. A., Nyamathi, A., \& Kington, R. (1997). Change in AIDS risk behavior among impoverished minority women after a communitybased cognitive-behavioral outreach program. Journal of Community Psychology, 25, 519-533.

Tulsky, J. P., Hahn, J. A., Long, H. L., Chambers, D. B., Robertson, M. J., Chesney, M. A., \& Moss, A. R. (2004). Can the poor adhere? Incentives for adherence to TB prevention in homeless adults. International Journal of Tuberculosis and Lung Disease, 8, 83-91.

Tulsky, J. P., Pilote, L., Hahn, J. A., Zolopa, A. J., Burke, M., Chesney, M., \& Moss, A. R. (2000). Adherence to isoniazid prophylaxis in the homeless: A randomized controlled trial. Archives of Internal Medicine, 160, 697-702.

Turner, B. J., Laine, C., Cosler, L., \& Hauck, W. W. (2003). Relationship of gender, depression, and health care delivery with antiretroviral adherence in HIV-infected drug users. Journal of General Internal Medicine, 18, 248-257.

White, M. C., Gournis, E., Kawamura, M., Menendez, E., \& Tulsky, J. P. (2003). Effect of directly observed preventive therapy for latent tuberculosis infection in San Francisco. International Journal of Tuberculosis and Lung Disease, 7, 30-35.

Wing, R. R., Phelan, S., \& Tate, D. (2002). The role of adherence in mediating the relationship between depression and health outcomes. Journal of Psychosomatic Research, 53, 877-881.

Yuan, K.-H., Bentler, P. M., \& Kano, Y. (1997). On averaging variables in a confirmatory factor analysis model. Behaviormetrika, 24, 71-83.

Zolopa, A. R., Hahn, J. A., Gorter, R., Miranda, J., Wlodarczyk, D., Peterson, J., et al. (1994). HIV and tuberculosis infection in San Francisco's homeless adults. Prevalence and risk factors in a representative sample. Journal of the American Medical Association, 272, 455-461. 